\title{
La fenomenología del cuerpo en Merleau-Ponty como superación del dualismo sartreano entre el ser en sí y el ser para sí
}

\author{
María Teresa Álvarez Mateos
}

Recibido: 5 de abril de 2016 - Aprobado: 20 de mayo de 2016

R

En este ensayo exploraremos la transformación de la fenomenología de la existencia que acontece en la obra de Maurice Merleau-Ponty, en relación con la obra de Sartre. Nos centraremos en el modo en que la fenomenología merleaupontiana supone un cambio de planteamiento respecto de la dualidad dominante en el existencialismo sartreano entre el ser-en-sí y el ser-para-sí, así como de la comprensión sartreana del para otro, atendiendo a los desplazamientos que se producen en el modo de entender el cuerpo, la existencia del otro y, por último, la libertad y la responsabilidad humanas.

Palabras clave: Merleau-Ponty, Sartre, existencialismo, fenomenología, cuerpo.

Artículo de reflexión. Este trabajo surge dentro del proyecto de investigación "El carácter trascendental de la hermenéutica fenomenológica y la posibilidad de la antropología filosófica", cuyo investigador principal es el profesor Ramón Rodríguez. Grupo de investigación Fenomenología y Hermenéutica, Universidad Complutense. El proyecto está financiado por el Ministerio de Economía y Competitividad de España. DOI: http://dx.doi.org/10.15332/s0120-8454.2016.0089.07

* Doctoranda en Filosofía de la Universidad Complutense de Madrid. Becaria del Programa de Formación del Profesorado Universitario (FPU) del Ministerio de Educación de España. Master en Estudios Avanzados de Filosofía, Universidad Humboldt de Berlín. Licenciada en Filosofía de la Universidad Complutense de Madrid. Licenciada en Filología Hispánica de la Universidad Nacional de Educación a Distancia (UNED). Dirección postal: Facultad de Filosofía, avenida Complutense s/n, Departamento de Filosofía Teorética ı. Correo electrónico: mt.alvarez@ucm.es. 


\title{
The phenomenology of the body in Merleau-Ponty as the overcoming of Sartrean dualism between being itself and being for itself*
}

\author{
María Teresa Álvarez Mateos**
}

\section{A bstract}

In this essay we examine the transformation of the phenomenology of existence that occurs in Merleau-Ponty's work in relation to Sartre's work. We will focus on how merleaupontian phenomenology means a change of proposal regarding the prevailing duality in sartrian existencialism between being-initself and being-for-itself, paying attention to the displacements that happen in the way of understanding body, other's existence and, finally, freedom and human responsibility.

Keywords: Merleau-Ponty, Sartre, existencialism, phenomenlogy, body.

Reflection paper. This work was generated within the research project "The transcendental character of phenomenological hermeneutics and the possibility of philosophical anthropology", whose main researcher is Professor Ramon Rodriguez from the Phenomenology and Hermeneutics Research group of Universidad Complutense. The project is funded by the Ministry of Economy and Competitiveness of Spain. DOI: http://dx.doi.org/10.15332/s0120-8454.2016.0089.07

* PhD student in Philosophy from Universidad Complutense de Madrid. Fellow of the Programa de Formación del Profesorado Universitario (FPU) of the Ministry of Education of Spain. Master in Advanced Philosophy Studies, from Humboldt University of Berlin. Degree in Philosophy from Universidad Complutense de Madrid. Degree in Spanish Philology from Universidad Nacional de Educación a Distancia (UNED). Address: Faculty of Philosophy, avenida Complutense s/n, Department of Theoretical Philosophy I. Email: mt.alvarez@ucm.es. 


\title{
La phénoménologie du corps chez Merleau-Ponty comme dépassement de la dualité sartrienne entre l'être en soi et l'être pour soi"
}

\author{
María Teresa Álvarez Mateos*
}

\section{Résumé}

Dans cet essai nous explorerons la transformation de la phénoménologie de l'existence qui a lieu dans l'œuvre de Maurice Merleau-Ponty, en relation avec l'œuvre de Sartre. Nous nous centrerons dans la façon dont la phénoménologie merleau-pontienne, suppose un changement d'approche face à la dualité dominante dans l'existentialisme sartrien entre l'être-en-soi et l'être-pour-soi, comme de la compréhension sartrienne du pour autrui, en faisant attention aux déplacements qui se produisent dans la façon de comprendre le corps, l'existence de l'autre et, finalement, la liberté et la responsabilité humaines.

Mots clés: Merleau-Ponty, Sartre, existentialisme, phénoménologie, corps.

Article de réflexion. Ce travail surgit dans le cadre du projet de recherche "El carácter trascendental de la hermenéutica fenomenológica y la posibilidad de la antropología filosófica", Le caractère transcendantal de l'herméneutique phénoménologique et la possibilité de l'anthropologie philosophique, dont le chercheur principal est le professeur Ramón Rodríguez. Groupe de recherche Phénoménologique et Herméneutique, Université Complutense. Le projet est financé par le Ministère d'Économie et Compétitivité d'Espagne. DOI: http://dx.doi.org/10.15332/s0120-8454.2016.0089.07

* Candidate au Doctorat en Philosophie de I'Université Complutense de Madrid. Boursière du Programme de Formation du Professorat Universitaire (FPU) du Ministère d'Éducation d'Espagne. Master en Études Avancées en Philosophie, Université Humboldt de Berlin. Licenciée en Philosophie de l'Université Complutense de Madrid. Licenciée en Philologie Hispanique de l'Université Nationale d'Éducation à Distance (UNED). Adresse postale: Facultad de Filosofía, avenida Complutense s/n, Departamento de Filosofía Teorética ı. E-mail: mt.alvarez@ucm.es. 


\section{La dualidad del ser en sí y el ser para sí, y el ser para otro en el existencialismo sartreano}

En El ser y la nada (1943) Sartre desarrolla la relación entre el ser-en-sí y el serpara-sí en tres momentos fundamentales: en primer lugar, presenta el problema del ser-en-sí como destino de la búsqueda ontológica del ser; en segundo lugar, expone el problema del ser-para-sí como un nuevo modo de plantear la filosofía de la conciencia en relación con el problema de la nada; por último, desplaza esta dualidad al problema de la alteridad, ocupándose del ser-para-otro. Nos detendremos brevemente en estos tres momentos, prestando atención también a los desarrollos de este dualismo en la Crítica de la razón dialéctica (1960).

Sartre plantea las relaciones entre el sujeto y el objeto, rechazando la donación completa del ser del objeto conocido a la conciencia, pero reconociendo al mismo tiempo la apertura de la conciencia y su capacidad para trascender hacia el sentido de este ser. Este sentido de ser permanece unido al objeto y no puede ser entendido como una abstracción que la conciencia añada al objeto. De este modo, Sartre diferencia el modo de ser de la conciencia (ser-para-sí) del modo de ser del fenómeno (ser-en-sí) como dominios diferenciados, sin suponer que la conciencia determina el sentido del fenómeno que aparece. La plenitud de ser del ser-en-sí se diferencia, por lo tanto, del modo de ser de la conciencia. Esta se caracteriza por la posibilidad de reflexionar sobre sí misma, dado que está atravesada por una negación ajena al ser-en-sí del fenómeno, que es completo y plenamente positivo. De este modo, la negación del ser o la "nada" se introduce en lo real por medio del ser propio de la conciencia, la cual posee esta negación como estructura constitutiva, por ser a distancia respecto de sí misma. ${ }^{1}$

La nada no es una mera negación añadida por el juicio, una propiedad negativa de la proposición. La nada vertebra lo real, afectando de la siguiente manera al modo de ser de los fenómenos: sin añadir ningún contenido a la estructura del en-sí, por ser justamente "nada" frente a la totalidad maciza del en-sí (que no admite ninguna adición de ser), limita a este último como pura negatividad. Es el fondo de nada, que resulta de un acto nihilizador por el cual las formas "se sumergen en la total equivalencia de un fondo" (Sartre, 1976, p. 21), sobre el cual el ser destaca a la percepción. Al no poder ser derivado del ser, mientras este sea plena positividad, ni poder ser tampoco el abismo de nada anterior al ser del cual

1 Sartre escribe El ser y la nada tras su lectura de Sein und Zeit, durante su estancia en Berlín (1933-1934). Sigue la conexión de las partes de la obra heideggeriana, dedicadas a la explanación de los existenciarios que componen la estructura del Dasein con el análisis de la temporalidad, de manera que lo que en un principio fue señalado como indicaciones metodológicas para señalar el camino por donde haya de ser elucidada la estructura del Dasein, cobra un nuevo sentido al incorporar la temporalidad a dicha estructura. En El ser y la nada la dialéctica entre el ser-en-sí y el ser para-sí resulta reinterpretada con la introducción del análisis de la temporalidad. Las dimensiones existenciales de pasado, presente y futuro están transidas de dicha dialéctica y, a su vez, explican el ser-en-sí-para-sí como modo de ser característico de la existencia humana: desde un pasado que es plenamente en-sí y acompaña al sujeto a modo de una sombra de facticidad irreductible hasta un futuro que es pura posibilidad y carece de la forma del en-sí. Si Heidegger daba primacía a la dimensión futura de lo advenidero en la estructura del Dasein, Sartre atenderá principalmente al presente, esa dimensión temporal propia del para-sí, por la cual la nada penetra en lo real, cerrando el modo de seren-sí de la existencia pasada, afirmando no ser ese en-sí pasado y, al mismo tiempo, proyectándose hacia el futuro, buscando en él compensar la carencia que le es constitutiva en cuanto negatividad. 
este surgiría sin ninguna mediación, la nada tendrá, por consiguiente, que ser introducida en lo real por el para-sí de la conciencia humana. Solo la introducción de la nada en el ser dota a la plenitud de ser del en-sí de una posibilidad de ser; y por ello, tampoco lo posible puede ser entendido como una mera cualidad del juicio opuesta a la necesidad en el orden lógico, sino que se trata de una parte constitutiva de lo real, germen de la angustia humana: "llamaremos angustia, precisamente, a la conciencia de ser uno su propio porvenir en el modo del no serlo" (Sartre, 1976, p. 34). En el estado de la angustia, el hombre toma conciencia de su apertura a la posibilidad, y con ello de su carencia de positividad plena de ser; toma consciencia, en definitiva, de su libertad.

Al ser el introductor de la nada en el ser, el para-sí posee la negatividad en su propia estructura. Sartre caracteriza esta negatividad al afirmar que la conciencia "es lo que no es y no es lo que es" (1976, p. 58), y esta doble negación se dirige hacia dos sentidos mutuamente relacionados: por un lado, en relación con la temporalidad, la conciencia es el futuro que todavía no es y no es el pasado que ya ha sido; ${ }^{2}$ por el otro, en relación con el conocimiento de la experiencia, la conciencia no es sino conciencia de una creencia y, sin embargo, no es esa misma creencia; es decir, la conciencia, dado que se distingue de los contenidos de sus creencias, contiene dentro de sí misma algo que la trasciende.

Partiendo del análisis husserliano del cogito prerreflexivo, Sartre nos muestra cómo en este se da, simultáneamente, la coincidencia de la creencia y el contenido de la creencia que excede la propia conciencia, de manera que nos resulta imposible acceder a estos contenidos de la creencia que exceden a la conciencia sin la mediación de esta última, esto es, sin que se nos muestren bajo la forma de la conciencia de una creencia. Por eso, afirma Sartre: "el ser de la conciencia consiste en existir a distancia de sí como presencia a sí, y esa distancia nula que el ser lleva en su ser es la Nada" (1976, p. 61). De esta falta de coincidencia, o doblez compuesta por la conciencia de las representaciones y los contenidos trascendentes de estas representaciones presentes, a la conciencia que se produce en el interior del para sí, se desprende que este sea un ser contingente volcado continuamente hacia su propia existencia, determinándose a sí mismo a existir para ser-en-sí. ${ }^{3}$

A partir de esta breve exposición de la estructura del ser-para-sí, podemos definir el conocimiento como un tipo de relación entre la nada del para-sí y la plenitud absoluta del en sí, en el que lo que se hace presente a la conciencia en la intuición es el en-sí que la conciencia no es, y esta negación tiene un carácter

2 Encontramos otro relato de esta negación de la negación en el primer volumen de la Crítica de la razón dialéctica, donde Sartre presenta la necesidad originaria y constitutiva del organismo que le empuja a trascender desde lo orgánico a lo inorgánico: una carencia en la relación original con una materia dada en su totalidad animaría la búsqueda de la reconstitución de dicha totalidad perdida: "la necesidad como negación de la negación es el organismo mismo viviéndose en el futuro a través de los desórdenes presentes como su posibilidad propia, y por consiguiente, como la posibilidad de su propia imposibilidad"( 1963, p. 235).

3 La necesidad del hombre de hacerse cargo de su propia existencia, de determinarse a sí mismo a ser, se anunciaba en el parágrafo 9 de Sein und Zeit: "Das Seiende, dessen Analyse zur Aufgabe steht, sind wir je selbst. Das Sein dieses Seienden ist je meines. Im Sein dieses Seienden verhält sich dieses selbst zu seinem Sein” (Heidegger, 2006, p. 41). 
trascendental: es necesario que la conciencia no sea el objeto para que pueda tener experiencia de él. Igualmente es necesario que la conciencia se niegue como en-sí pasado, para abrir hacia sus posibilidades futuras. El para-sí "pone" al objeto que aparece ante él como diferente a él, introduce la negación sin añadir nada al fenómeno conocido: conocer es constatar un "hay", afirmar que haya ser. En su obra póstuma Verdad y existencia, Sartre reconoce, sin embargo, que sí hay una dimensión de ser que el para-sí añade al ser por medio del conocer: la luminosidad. Así, definirá en esta obra la verdad como "cierta dimensión que viene al ser por la conciencia" $\left(1989\right.$, p. 53). ${ }^{4}$

En la tercera parte de El ser y la nada, Sartre introduce una nueva dimensión del ser: el para otro. "Necesito del prójimo para captar por completo todas las estructuras de mi ser: el Para-sí remite al Para-Otro" (1976, p. 144). ¿Qué significa el "otro" en nuestra experiencia del mundo? Captamos en la existencia ajena una nueva negación: el otro no soy yo. Su existencia no es una hipótesis que haya que probar, sino una facticidad contingente y primera. Hay una relación primera de mi conciencia con la del prójimo, distinta a la relación que se da en mi conocimiento de los objetos, en la cual el otro se me da directamente como sujeto, es decir, dotado de un modo de ser idéntico al mío. Esa relación se realiza en la experiencia de la mirada. La aparición del otro en mi campo perceptivo produce la desarticulación de los elementos que componían mi universo antes de su llegada; en torno a él se organizan y reagrupan las relaciones de distancia que guardo con los objetos que median entre ambos. Sin embargo, yo no puedo captar las cosas que median entre el otro y yo, tal y como las percibe él: la realidad ante mis ojos se dirige ahora a un punto de fuga al que se dirigen los objetos, como si fuera un "vaciadero" en el cual estos se me escapan en una percepción de la que estoy privado. Y yo mismo me vuelvo susceptible de ser convertido en objeto bajo la mirada del otro, como también él es potencialmente objeto de mi mirada. La conversión del otro en objeto es una "degradación" de la relación originaria en la que el otro y yo nos percibimos recíprocamente como sujetos libres. ${ }^{5}$ La libertad e imprevisibilidad del otro intensifica mi vulnerabilidad a que él me convierta en objeto y, por otro lado, resiste a su conversión en objeto bajo mí mirada.

Libertad y objetivación son, pues, los dos polos opuestos entre los cuales se mueve mi relación habitual con el otro. Mi objetivación supone la alienación de mis propias posibilidades en relación con el mundo, las cuales son cegadas, trascendidas, por las posibilidades del otro:

4 La idea ya se anunciaba en El ser y la nada: ante el para sí, el ser se destaca rodeado de un fondo de nada.

5 En el primer volumen de la Crítica de la razón dialéctica (1960), Sartre adoptará una nueva perspectiva en relación con esa situación originaria de reciprocidad en mi relación con el otro, luego quebrantada: la reciprocidad como relación en el interior de la totalidad solo puede ser aprehendida según el punto de vista de la totalidad. Será en esta obra donde se lleve a cabo una crítica del conocimiento dialéctico que cuestione la legitimidad de la superación del conocimiento humano en una totalidad. Si bien en El ser y la nada Sartre presenta la totalidad —tanto en relación con la temporalidad, como en relación con el conocimiento y las relaciones con el otro- como un estado inicial perdido e irrecuperable, cuya pérdida alienta la huida del para sí hacia sus posibilidades y lo convierte en individuo libre, en la Crítica, invertirá el planteamiento, situando el punto de partida en la acción del individuo singular y considerando la construcción de la totalidad como producto histórico y contingente, sometido a continuas destrucciones y reconstrucciones, y sellado por medio de dispositivos que garantizan su conservación, como los juramentos y las instituciones. 
mi posibilidad se convierte, fuera de mí, en probabilidad. En tanto que el prójimo la capta como roída por una libertad que él no es, de la que él se hace testigo y cuyos efectos calcula, es pura indeterminación en el juego de los posibles. (1976, p. 168)

En la Crítica de la razón dialéctica, Sartre explorará el modo en que se produce el encuentro entre los hombres en el devenir histórico y traducirá este peligro inherente a la forma de ser-para-otro en la noción de rareza, la cual está presente en la realidad humana desde su estado de perentoriedad en relación con la materia orgánica. El carácter histórico de las relaciones humanas subraya en esta obra la facticidad y contingencia de la existencia del otro, sin que puedan entenderse estas relaciones bajo la forma de una constitutiva "abertura al otro que se actualizaría en algunos casos particulares" (1963, p. 254).

El espacio en que nos encontramos el otro y yo ya no puede ser entendido como una totalidad, está transido de nada, debido a esta dualidad de negaciones: mi negación del otro como sujeto y la suya respecto de mí. Sin embargo, dijimos que la relación originaria era nuestra consideración recíproca como sujetos, de modo que no cabe entender esta nada como fundamento inicial del que brota la pluralidad de conciencias, sino que hay que considerar que ambas, la multiplicidad de conciencias y esta negatividad, aparecen a la vez. Volvemos así a la contingencia pura e irreductible de la facticidad del otro. Los objetos que somos uno respecto del otro se manifiestan como cuerpos. "Podría definirse el cuerpo como la forma contingente que la necesidad de mi contingencia toma" (1976, p. 194); por ser contingente, el cuerpo no es un en-sí en el para-sí, no es algo separado de este último, sino la dimensión del mismo respecto de la cual el para-sí no es fundamento. En el análisis del conocimiento hemos visto cómo el para sí no se encuentra separado del mundo, sino abierto hacia él; el cuerpo es en este sentido la posibilidad de orientación del para sí en el mundo, no solo percibiendo sino también actuando en él. Por no ser algo separado del para-sí, no puedo captar mi cuerpo como capto el resto de objetos del mundo. Mi cuerpo es mi lugar en el mundo, la perspectiva desde la cual percibo el resto de objetos que me rodean. ¿De qué manera capto, entonces, mi cuerpo?

Puedo hacerlo reconstruyéndolo, por analogía, con el cuerpo del otro, al que veo convirtiéndose en instrumento, ingresando en el plexo de relaciones de utilidad; o bien, abstrayendo, por medio del pensamiento racional y universalizador, mi perspectiva particular, suprimiendo la diferencia entre los diversos puntos de referencia coexistentes en el mundo y reconstruyendo el instrumento que soy, esta vez a partir de las indicaciones del resto de instrumentos del mundo. Disuelvo así mi centro de referencia particular en un centro de referencia absoluto, de manera que mi conciencia queda sobrevolando al mundo sin poder ya integrarse en él. Finalmente puedo, también, entender mi cuerpo no como conocido, sino como vivido, como soporte de mis acciones. Es por esta tercera vía por la que comprendemos nuestro cuerpo, a partir de nuestro trato originario con el mundo, en lugar de tomarlo como punto de partida para analizar cómo captamos el mundo a través de él. Trascendiendo continuamente hacia 
los objetos del mundo, mi cuerpo persigue recuperar el para sí, buscando en lo concreto elecciones qué realizar, para compensar la imposibilidad de darme un fundamento, que viene dado por la facticidad irreductible del cuerpo que soy desde mi nacimiento. El cuerpo, además, es el soporte de mi pasado en el presente, de modo que la trascendencia hacia el resto de objetos del mundo es también una huida respecto de mí en-sí pasado. En el movimiento hacia lo concreto, puedo captar de súbito la contingencia que soy, sentir que todo lo que me rodea es gratuito: es el estado al que Sartre denomina náusea. ${ }^{6}$

El equivalente de las dos modalidades ontológicas del ser-para-sí y el ser-paraotro es el ser cuerpo y ser objeto para otro. Como veíamos, al reconstruir mi cuerpo a partir del cuerpo del otro, lo contemplo como un instrumento inserto en relaciones de utilidad en el mundo. Del mismo modo, mi cuerpo se convierte en utensilio para el otro. Como utensilio, ese cuerpo ajeno me es dado como el en-sí puro del ser del otro: un en-sí entre otros en-síes, al que trasciendo hacia mis posibilidades, y empero - a diferencia del resto de objetos componibles-, un cuerpo al que percibo como una totalidad, que no mantiene con el resto de objetos relaciones de pura exterioridad, pues en ese caso hablaríamos de cadáver y no de cuerpo, sino que lo capto como centro de referencia de las relaciones que mantiene con las cosas. No obstante, ciertas formas de conducta con el otro pueden suprimir mi visión del mismo como totalidad diferente al resto de objetos, como sucede en el sadismo. Mi relación con el otro hará del mismo una totalidad continuamente destotalizada. En la experiencia de la enfermedad, Sartre encuentra un tipo aberrante de modo de ser mi cuerpo para mí mismo: a través del dolor, llego a experimentar mi propio cuerpo desde el punto de vista del prójimo. Esta posibilidad de dirigir hacia mí mismo la mirada del otro sobre mi cuerpo es un hecho que no puede deducirse ni de las estructuras del ser-para-sí ni del ser-para-otro. Si el para-sí soy yo, tal y como yo me veo, o el otro, tal como él se ve, el para otro soy yo, tal como el otro me ve, o el otro, tal como yo lo veo. La dialéctica entre el para-sí, que es pura huida, y el anquilosamiento en el en-sí se vuelve relación circular, ${ }^{7}$ bajo la nueva dimensión de mi ser-paraotro: la libertad del otro me muestra mi imposibilidad de ser fundamento de mí mismo; de captarle como libre, sin volverme yo mismo objeto; convierte la huida de mi para-sí en un proyecto de asimilación del prójimo, de concebirme desde su mirada. De manera análoga, podremos distinguir en la dimensión del nosotros un nos-objeto, en la medida en que somos objetos en común

6 "La Náusea no está en mí; la siento allí, en la pared, en los tirantes, en todas partes a mi alrededor. Es una sola cosa con el café, soy yo quien está en ella" (Sartre, 2008, p. 17).

7 El círculo que va desde mi conversión en objeto ante el otro, sujeto a la recuperación de mi subjetividad y la conversión del otro en objeto. Esta relación puede tomar formas muy divergentes: las reacciones de la vergüenza y su correlato: el orgullo, el temor, la experiencia del amor, en la cual deseo la libertad del otro y, al mismo tiempo, erigirme en límite de esa libertad, de manera que mi ser para otro tenga, para él, preeminencia sobre su propia libertad, convirtiéndome para él en "el objeto-fondo sobre el cual el mundo se destaca"(Sartre, 1976, p. 230); la experiencia de la seducción, en la cual me convierto en objeto puesto bajo su mirada; la realidad del lenguaje, que constata la inexistencia de una intersubjetividad entre el prójimo y yo, y supone la fuga de mis pensamientos hacia una forma objetiva para el otro; la contemplación de los amantes bajo la mirada de un tercero, que hace que cada uno de aquellos experimente la objetivación de sí mismo y del otro; la actitud masoquista, en la cual uno de los dos se compromete a no ser nada más que objeto frente a la radical libertad del otro; $y$, por último, el sadismo como radicalización de "la tentativa original para apoderarme de la libre subjetividad del Otro a través de su objetividad-para-mi", que es el deseo sexual y el énfasis de la apropiación del otro como mero instrumento. 
para un para-sí, y nuestras respectivas posibilidades se alienan ante un tercero. Es la circularidad de mi relación con el otro ampliada, el nos-objeto desaparece cuando reivindica su libertad frente a los terceros que lo objetivan y les devuelve la mirada. Cuando tengo la experiencia de una trascendencia común con los otros hacia ciertos fines e instrumentos del mundo, "esta experiencia es de orden psicológico y no corresponde en modo alguno a una unificación real de los para-sí" (Sartre, 1976, p. 262), es decir, no existe un nosotros-sujeto como tal, la subjetividades siguen estando radicalmente separadas. Aceptar la existencia de un nosotros-sujeto supondría rechazar el modo de ser para otro, tal y como lo hemos expuesto.

Encontramos una exposición historizada del paso del nos-objeto al nosotrossujeto, al final del primer volumen y el comienzo del segundo que componen la Crítica de la razón dialéctica. Frente a la forma de ser pasiva de la serie o el colectivo, agrupado y dotado de totalidad relativa de manera puramente exterior, Sartre presenta la forma de ser del grupo como comunidad de individuos orientados a la consecución de fines comunes por medio de la acción. Reconoce aquí, entonces, frente a lo expuesto en El ser y la nada, la existencia fugaz de un nosotros-sujeto. Se trata de una construcción histórica, continuamente amenazada por la disolución de sus miembros en la forma de la serie, que huyendo de la vuelta al colectivo inventa dispositivos, como los juramentos y las instituciones, que terminan por petrificar al grupo en lo práctico inerte y lo devuelven al modo de ser de la serie. En el transcurso de la obra sartreana se radicaliza, en definitiva, la negación de la perspectiva de la totalidad, sobre todo a partir de la consideración de la inserción del ser en la historia: "la aventura humana no está terminada mientras quede un hombre para conferirle su sentido y después se hunda en la nada por falta de testigos"' (Sartre, 1989, p.158).

\section{El cuerpo y la existencia del otro en Merleau-Ponty}

En el último capítulo de la primera parte de la Fenomenología de la percepción, Merleau-Ponty encuentra un fenómeno a partir del cual se pueda dejar atrás, de una vez por todas, la tradicional dicotomía entre sujeto y objeto: el lenguaje, en general, los actos de significación. Si, como afirmaba Sartre, el lenguaje presupusiera un pensamiento previo, que fuese robado y objetivado para entregárselo al otro, no podríamos comprender por qué mi pensamiento fluye hacia su expresión como su cumplimiento. El pensamiento se presenta a nosotros a través del habla interna o externa, por medio de su expresión nos apropiamos de él. Para el pensamiento precientífico, nombrar las cosas significa causar o modificar su existencia. El que escucha, por su parte, recibe el pensamiento a través del habla de otro, pero si solo pudiera comprender el lenguaje que ya conoce previamente, la experiencia de la comunicación sería una ilusión. Tenemos, en realidad, la capacidad de captar el pensamiento del otro a través del lenguaje, una capacidad de pensar de acuerdo a los otros que enriquece nuestro 
propio pensamiento, de manera que en el diálogo podemos comprender más de lo que hemos pensado con anterioridad. Será por medio de dicha capacidad que podamos aminorar la imposibilidad, declarada por Sartre, de conocer la perspectiva que el otro tiene sobre el mundo.

El sujeto que habla no visualiza ni piensa previamente sus palabras, estas no son un signo que el hablante añada a un pensamiento previo; por el contrario, este conoce su articulación y el modo de proferirlas como uno de los posibles usos de su cuerpo, análogamente al modo como el músico adquiere el conocimiento de su destreza a partir del uso de su instrumento. El lenguaje es, en este sentido, un poder de expresión del cuerpo con el cual podemos, entre otras cosas, proyectar nuestro pasado hacia el presente. No es una mera técnica para designar cosas o pensamientos - como aparece definido en varios pasajes de la Crítica de la razón dialéctica-, sino el modo por el cual el sujeto toma una posición en el mundo, que abre nuevas dimensiones de experiencia; es la existencia externa del sentido. Por su parte, el pensamiento no es algo interno que exista con independencia del lenguaje y el mundo. La capacidad para expresar nuevos sentidos a partir de palabras de las que ya disponemos es equivalente al gesto que adoptamos en la adquisición de un nuevo hábito. Y esta posibilidad transformadora permite la comunicación. Merleau-Ponty aclara que el habla convencional, en la cual los interlocutores intercambian expresiones compartidas y reconocidas por ambos, es una forma tardía de comunicación: es necesario retrotraer el estudio del lenguaje a los estadios anteriores de aquella, donde desempeñan un papel clave el gesto y el contenido emocional de las palabras (1993, p. 199). ${ }^{8}$ El lenguaje transido de la experiencia vivida en la que toma su forma es el lenguaje de la acción, pero también el de la música y la poesía.

La propuesta merleau-pontiana del modo en que se dan las relaciones con otros sujetos pasa por radicalizar el momento, reconocido por Sartre, en el cual el cuerpo del otro ya no puede ser comprendido como un fragmento del mundo y se convierte en un punto de fuga en torno al cual el mundo se organiza de una cierta manera. En la experiencia del diálogo, el otro ya no es un pedazo de mi campo de acción ni yo tampoco lo soy para él: somos colaboradores uno para otro en una relación de reciprocidad, en la cual nuestras perspectivas sobre el mundo convergen y vivimos en un mundo compartido. En ausencia de reciprocidad, comienza la dinámica retratada por Sartre: el otro me convierte en objeto hasta que recupero mi libertad y lo convierto a él en objeto. Pero esto solo sucede si los dos miramos al otro con una mirada inhumana, si cada uno de los dos cree que sus acciones no están siendo consideradas y comprendidas por el otro, sino observadas como si fueran los movimientos de un insecto. ${ }^{9}$ Pero incluso aunque algo así llegara a suceder, la objetivación del otro solo sería insuperable mientras siguiese ocupando el lugar de cualquier comunicación posible, y también habría comunicación entre ambos en la ausencia de comunicación. Incluso en la supresión del diálogo sigue conservándose el lenguaje socialmente construido en el 
habla interna. En el trato con el mundo hemos aprendido a movernos en él, en compañía de otros, y esos hábitos adquiridos se mantienen también en soledad; sobre ese modo de estar en el mundo hemos construido nuestro conocimiento, de manera que pensar es siempre pensar con la comunidad.

En Lo visible y lo invisible, Merleau-Ponty introduce la noción de carne (chair): el ser carnal que constituye el mundo visible es un ser de profundidades, que contiene diferentes niveles y caras, algunas latentes y otras manifiestas, y del cual nuestro cuerpo sensible no es sino una variante. Nuestro cuerpo tiene dos caras: una sensible u objetiva y otra sentiente, que con Sartre llamábamos para sí. En realidad, no se trata de "dos lados" propiamente dichos, como si el lado sensible fuese un objeto más, conectado con otros objetos del mundo. Nuestro cuerpo ni es solo mirada ni tampoco es solo contemplado por otro, sino más bien una visibilidad en ocasiones extraviada y en ocasiones recobrada. La visibilidad y el tacto no son un movimiento unidireccional que se dirija desde el cuerpo hacia las cosas ni tampoco una propiedad que les pertenezca a ellas con anterioridad al acto de la visión y el tacto. Son, por el contrario, actos que se constituyen entre el sujeto que mira y las cosas miradas, de forma recíproca, de manera que no podemos propiamente hablar de un sujeto que mira un objeto mirado sino de dos que se miran. Esta era la situación originaria e irrecuperable que Sartre anunciaba en la mirada del otro. ${ }^{10}$ Merleau-Ponty sigue afirmando, con Sartre, que la operación de la visión tiene lugar dentro de mí, dentro de mi campo perceptivo, y que aún no hemos liquidado la dificultad de cómo sea accesible el campo perceptivo del otro, al margen del testimonio que me llega de él por su palabra. La solución merleau-pontiana a este escollo será el quiasma. Para llegar a esta respuesta será necesario renunciar a la bifurcación del parasí y el en-sí, rechazar la idea según la cual mi cuerpo es un objeto dado a una conciencia, y mi para-sí, una unidad centrífuga a la que irían a parar - modo de punto de fuga - otros para sí, que a su vez serían "vaciaderos" en los que se perdería mi campo perceptivo. Mi conciencia está sostenida por la unidad prerreflexiva y preobjetiva de mi cuerpo. Nuestro mundo privado no está meramente yuxtapuesto al mundo de los otros, sino rodeado por ellos y constituyendo, junto a ellos, un sentiente en general ante un mundo sensible compartido. "Or, cette généralité qui fait l'unité de mon corps, pourquoi ne l'ouvrirait-elle pas aux autres corps?" (Merleau Ponty, 1964, p. 187). Si puedo sentirme a mí mismo tocado al mismo tiempo que me toco, ¿no se podría dar una relación semejante entre diferentes cuerpos? Así llega Merleau-Ponty a afirmar el quiasma: "adhérence charnelle du sentant au senti et du senti au sentant" (1964, p. 187). De este modo, entendiendo lo visible como reversible y no como propiedad de una conciencia, podemos pensar en dos cuerpos cuyos campos perceptivos se fundan, cuyas acciones y pasiones encajen plenamente. De este modo ha quedado abierta, gracias a la reversibilidad de lo visible o lo tangible, un ser intercorpóreo, que se

10 Si bien Sartre reconoce esta mirada entre dos sujetos humanos, pareciera que la noción de carne visible merleaupontiana no excluyese la posibilidad de que se diese un acto de visión entre otro tipo de sentientes. No obstante aclararemos que si bien la visión y el sentido en general constituyen la condición de posibilidad del pensamiento, este era, como veíamos, constitutivamente lingüístico, de manera que si bien podría reconocerse el fenómeno de la mirada en los animales, en el caso del pensamiento tendría que reconocerse, en primer lugar, su capacidad lingüística. 
extiende más allá de las cosas que yo y el otro vemos y tocamos por separado. Si Sartre reconocía una relación circular entre ambos, en Lo visible y lo invisible, Merleau-Ponty confiere a este círculo una reversibilidad, hace de él quiasma. Al mismo tiempo, esta estructura repercute en el modo en que comprendo mi propio cuerpo: me vuelvo reversible también para mí mismo. De este modo mi cuerpo puede, al fin, relacionarse con otro cuerpo y no de manera solitaria en relación con mi mundo privado.

Los diferentes niveles y tejidos que presenta la carne se deben, en parte, a la huella que resta en lo sensible tras haber sido visto o tocado. La carne (chair) misma es en la forma de ese quiasma: volviendo continuamente sobre sí misma. ${ }^{11}$ El pensamiento se convierte en una relación tridimensional entre el yo, el mundo y el otro; las relaciones de reversibilidad se producirán también en la palabra hablada. ¿Cómo se conecta la carne con la idea, lo visible con el pensamiento? La respuesta viene dada por el ámbito de las emociones y el arte: la literatura, la música, los sentimientos, y nuestra experiencia en el mundo en general permiten explorar lo invisible que se halla escondido en la carne, desvelar las ideas. Las ideas invisibles a las que accedemos por medio del arte son de tal naturaleza que el acceso a ellas nos quedaría vedado si no fuera por nuestra sensibilidad; no las captamos directamente por medio de los sentidos $y$, sin embargo, se encuentran incrustadas en lo sensible, detrás de la carne o en medio de ella. Podemos decir entonces que la carne, pese a ser sensible, está transida y articulada por haces de invisibilidad y que las ideas no son realidades alienadas respecto de la materia, sino elementos invisibles que le dan forma.

Del suelo de nuestra experiencia del ser, originaria y prerreflexiva, brota luego el mundo tal y como lo vemos ahora constituido; en el arte también encontramos una experiencia originaria a pesar de que en él nos orientemos hacia objetos que no se nos dan en la experiencia cotidiana y que salen a la luz justamente en nuestra experiencia de ellos. Si nos consideramos insertos en el mundo rodeados de símbolos, instrumentos, seres vivos y otros prójimos, y tratamos de comprender qué nos sucede en esa situación, podemos llegar a una primera verdad: hay una presencia, hay algo y alguien ahí. ${ }^{12}$ Entendiendo la cosa como un nudo de propiedades engarzadas formando una unidad, como objeto o ensí, ¿cómo podemos explicar nuestro contacto con las cosas? ¿Puede haber tal contacto? La respuesta a ambas preguntas supone un segundo giro importante de Merleau-Ponty respecto de Sartre: la cosa entendida como en-sí, como objeto pleno de ser es el resultado de una segunda interpretación de la experiencia. ${ }^{13}$ La plena positividad de ser del fenómeno se planteaba al comienzo de $\mathrm{El}$ ser y la nada como destino de la búsqueda ontológica del ser: se afirmaba dicha

11 Merleau-Ponty reconoce que lo que él llama carne no ha recibido ningún otro nombre a lo largo de la historia de la filosofía, y advierte contra los ensayos de considerarla como sujeto o como sustancia: es más bien un elemento, "emblèm concret d'une mannière d'être générale" (Merleau Ponty, 1964, p.191).

12 "Notre première vérité, - celle qui n'est préjuge rien et ne peut être contéste-sera qu'il y a présence que 'quelque chose est là et que 'quelqu'un' est là" (Merleau-Ponty, 1964, p. 210).

13 "À partir des choses prises dans leur sens natif, de noyaux identifiables, mais sans aucune puissance propre, on ne parvient à la chose- objet, à l' ENSOI, à la chose identique à elle-même, qu'en imposant à l'expérience un dilemme abstrait qu'elle ignore" (Merleau-Ponty, 1964, p. 212). 
positividad plena como un principio y se distinguía de la nada del para-sí. Frente a dicha postulación, Merleau-Ponty propone partir del sentido originario que nos formamos de las cosas, sin concederles a estas ningún poder en sí mismas, ninguna capacidad de autoconservación que contraste con la impotencia de autofundamentarse del para-sí. La identidad de la cosa resulta en Merleau-Ponty de un razonamiento trascendental: podemos hablar de las cosas solo a condición de que estas se comporten como si tuvieran un principio interno de unidad. En terminología sartreana diríamos ahora que es por nuestra adición de nada a lo real por lo cual percibimos las cosas como siendo en-sí, de manera que la caracterización del objeto como plenitud de ser, solo es un retrato del mismo como este es para nosotros. El fenómeno así entendido es la imagen que obtenemos proyectándola en un escenario sin espectador, no es la cosa que captamos en nuestra experiencia originaria, en la cual tenemos que estar siempre presentes y tratando con las cosas, sino la cosa hipostasiada y desnaturalizada frente a nuestra propia autodestrucción.

El carácter secundario y artificial de este proceso de nihilización del para sí frente a la plenitud de ser del en sí queda establecido afirmando el carácter trascendental de nuestra experiencia originaria en el mundo, en la cual estamos abiertos hacia algo y constatamos, ante todo, que "hay" ese algo: es nuestra experiencia de las cosas y del mundo en general la base que necesitamos para poder pensar la nada en algún sentido. El carácter trascendental de nuestra experiencia en el mundo, que antes mencionábamos como respuesta al problema del solipsismo - la soledad del individuo siempre es secundaria respecto de una primera experiencia de trato con sus semejantes -, es ahora la razón que nos lleva a negar que la nada sea nuestro carácter constitutivo y originario, y la plenitud de ser, un privilegio originario de las cosas.

\section{Valoración de una transformación en la fenomenología de la existencia}

Una vez expuesta la solución de Merleau-Ponty al salto insalvable entre el ser-en-sí y el ser-para-sí sartreano, podemos volver la vista atrás y valorar dicho dualismo así como la propuesta de su disolución o, mejor dicho, de la negación de su carácter primero y fundamental. En su libro De Sartre a Merleau-Ponty: dialéctica de la libertad y del sentido, Eduardo Bello recoge las consideraciones del vínculo de este dualismo con el cartesianismo, que expone De Waelhens en Une philosophie de l'ambigüité: "la imposibilidad de la síntesis final, en-sí-para-sí, adolece del mismo dualismo cartesiano que acusa el problema de la unión del alma y el cuerpo" (Bello, 1979, p. 19). En efecto, pese a los intentos de Sartre por desprenderse de la filosofía idealista de la conciencia a partir de la consideración del cuerpo en situación, inserto en el mundo y tratando con las cosas, la dualidad entre el ser-en-sí y el ser-para-sí está presente también en la tercera parte de El ser y la nada, y pese a la afirmación sartreana de que el ser-para-otro es un modo de ser fundamental e irreductible al ser-en-sí y al ser-para-sí, hemos 
visto cómo el para-otro puede considerarse, estructuralmente, como un doble del para-sí, no dirigido hacia mí mismo, no el sí que soy para mi propia conciencia, sino para la conciencia del otro.

Asimismo, la relación entre plenitud de ser y nada, que caracteriza al vínculo entre el en-sí y el para-sí, se inmiscuye también en mis relaciones con el otro, si bien invertida con una revalorización del poder que ostenta el ser para la conciencia, plenamente libre, frente al ser en-sí del objeto, pleno de ser, pero completamente determinado: o me convierto en objeto bajo su mirada, o recupero mi libertad y lo reduzco al rango de objeto. En la relación con el otro se muestra el poder de dominio que posee la nada sobre el ser, se acentúa mi deseo de volverme nada, de convertirme en la mirada del otro sobre mí. ${ }^{14}$ En su “Introducción" a Verdady existencia, Celia Amorós expresa este esfuerzo de la conciencia por seguir siendo ella misma como "una especie de conatus" y subraya el hecho de que para Sartre el peso de la estructura ontológica en-sí-para-sí recaiga siempre sobre el para-sí. Por otra parte, Bello señala que si bien tanto Sartre como Merleau-Ponty parten de una reivindicación de la experiencia de ser-en-el-mundo contra el idealismo de Brunschvicg predominante en el panorama intelectual francés de su época, será Merleau-Ponty quien lleve hasta sus últimas consecuencias la experiencia vivida, frente al repliegue sartreano a la filosofía de la conciencia ${ }^{15}$. En este sentido nos parece plenamente acertada la consideración de Bello según la cual la diferencia más profunda entre ambos autores es el paso de la existencia individual y el subjetivismo individualista de El ser y la nada a la coexistencia social desde el planteamiento pluralista de lo real merleau-pontiano. Al reflexionar sobre el fenómeno del lenguaje, hemos expuesto en qué medida la experiencia social es para Merleau-Ponty la condición trascendental de la experiencia individual. Podemos añadir que la presencia de los otros se produce incluso en la experiencia originaria de trato con las cosas, pues estas han sido ya tocadas y vistas por otros. Como veíamos la tangibilidad y visibilidad inscritas en lo real hacen de la carne un tejido complejo con pluralidad de rostros. En su exposición de las divergencias entre ambos pensadores, Bello acentúa la unidireccionalidad de la crítica, que se dirige, en exclusiva, desde Merleau-Ponty a Sartre y atañe especialmente a la superación del dualismo entre el en-sí y el para-sí que hemos expuesto en el parágrafo anterior, y la crítica merleau-pontiana a la idea de libertad en Sartre, que veremos al final de este ensayo ${ }^{16}$.

14 Incluso cuando en la Crítica de la razón dialéctica abandona de manera frontal el problema de la conciencia y pasa a ocuparse en exclusiva del terreno práctico e histórico, Sartre sigue defendiendo la absoluta singularidad e individualidad originarias del sujeto que resultaron de sus análisis en El ser y la nada. Por otra parte, la acción individual, entendida como dirección del sujeto, proyectándose hacia determinados objetos y fines del mundo, sigue obedeciendo al esquema de la dirección de la conciencia hacia el mundo. En esta fase, como señala Bello, "la lucha por arrancar de raíz su idealismo (filosofía de la subjetividad) es correlativa de esta otra lucha por plantear la posibilidad de un compromiso efectivo en la actual situación socio-histórica" (1979, p. 50), y añade: "la evolución del pensamiento de Sartre puede resumirse así: de $L$ Étre et le Néant a la Critique solo existe el paso que ha de dar el individuo para comprenderse e insertarse en la sociedad. Pero ¿se ha dado el "paso"?" Hemos indicado las razones por las que coincidimos con Bello en constatar que en la Critique no se ha superado la contradicción presente en lo real. "De ahí —concluye Bello- la dificultad del compromiso en la situación histórica, de ahí la solución frecuente en lo imaginario o lo irreal, de ahí el riesgo inherente a una "filosofía de la subjetividad" (1979, p 51). conscience est un être dont l'essence implique l'existence" (1966, p. 66). 
Encontramos una nueva reflexión acerca de qué se entienda por superación del en-sí-para-sí sartreano en los Apuntes Antropológicos basados en una relación: Maurice Merleau-Ponty y Jean-Paul Sartre de Carmen López Sáenz. "Sartre no superará la dialéctica hegeliana de los contrarios, mientras que la hiperdialéctica de Merleau-Ponty, en tanto que movimiento interior, trascenderá los dualismos y la ambivalencia hegeliana de lo teológico y lo antropológico" (Sellés, 2004, p. 83). Hemos expuesto en el parágrafo anterior el modo en que el dualismo presente entre el en-sí y el para-sí y en las relaciones con el otro, era considerado por Merleau-Ponty como una experiencia secundaria derivada de la experiencia vivida. Ahora nos preguntaremos cómo ha quedado transformado ese dualismo a partir de ser considerado de este modo. La "trascendencia" a la que alude la autora se trata de un regreso hacia aquello que es previo y trascendental en relación con las divisiones sartreanas. No ha de entenderse, sin embargo, que en esa experiencia vivida se anule por completo el papel de la conciencia, como si Merleau-Ponty invirtiese el peso de la relación y diese al cuerpo el carácter trascendental que otrora Sartre atribuía a la conciencia. ${ }^{17}$ El cuerpo es mi existencia encarnada y como tal mi exterioridad, "es un mediador de la continuidad eidética con el mundo" (López Sáenz, 2003, p.93), así como el lenguaje es la expresión del pensamiento. Si por medio de las expresiones artísticas, ${ }^{18}$ captábamos las ideas como articulaciones invisibles de lo real, si por medio de la filosofía interrogábamos a lo invisible que se esconde tras el ser, podemos comprender, ahora, que este proceso de expresión que realizo en mi cuerpo lo es por relación con un fondo de invisibilidad previamente "inexpresado"; ¿una subjetividad?, ¿sigue siendo operativa la distinción entre subjetividad y objetividad en la fenomenología de Merleau-Ponty?

La respuesta parece ser negativa: como veíamos en Fenomenología de la Percepción, el filósofo introducía el fenómeno del lenguaje como vía para la superación de la tradicional distinción entre sujeto y objeto. No se trata meramente de que las palabras - corpóreas - expresen un pensamiento invisible y anterior: ese pensamiento no nos sería conocido si no fuese por su verbalización. ¿Cabe hablar entonces de una subjetividad anterior a su encarnación en el cuerpo, siquiera como fondo de invisibilidad?, ¿no ha afirmado en Lo visible y lo invisible que el verdadero trascendental es la experiencia vivida en un cuerpo encarnado? En Merleau-Ponty cuerpo y conciencia forman una unidad que sólo abstractamente

No obstante, no encontramos citas explícitas a este último en la Critique, a excepción de una referencia en la página 73 de las Cuestiones de Método: "Cuando decimos: sólo hay hombres y relaciones entre los hombres (añado para Merleau-Ponty: también cosas y animales, etc.), sólo queremos decir que el soporte de los objetos colectivos tiene que buscarse en la actividad concreta de los individuos; no negamos la realidad de esos objetos, pero pretendemos que es parasitaria". Es la única excepción a la generalización que hace Bello: "Sartre dedicará un solo artículo a Merleau-Ponty [...] Merleau-Ponty vivant [...].En él la intención crítica está, por supuesto, ausente” (Bello, 1979, p. 53).

17 En Hermenéutica del cuerpo doliente-dolido desde la fenomenología del sentir, López Sáenz responde a las interpretaciones de quienes como Zaner, en The Problem of Embodiment, y Kwant, en The Phenomenological Philosophy of Merleau-Ponty, han acusado a Merleau-Ponty de disolver el espíritu en el cuerpo: "en nuestra opinión que se hallen unidos no significa que uno de los dos desaparezca. Hay una dialéctica circular entre lo "espiritual" y el cuerpo que nuestra tradición dualista ha considerado accidental" (López Sáenz, 2003, p. 93).

18 En su trabajo Merleau-Ponty o el arte de la visibilidad, López Sáenz explora las posibilidades de la fenomenología merleau-pontiana en el terreno de la estética, partiendo del artículo del filósofo francés titulado La douté de Cezánne. El pintor hace visible para todos ese visible virtual que podíamos denominar esencia, y que no es sino la carne del mundo. 
puede ser separada. La perspectiva de Merleau-Ponty en relación con el problema de la subjetividad coincide en muchos aspectos con la que se plantea en la última filosofía de Husserl. Como el filósofo francés recuerda en una nota al pie al final de la segunda parte de su Fenomenología de la Percepción, en su obra tardía Husserl considera que toda reflexión debe regresar a la descripción del mundo de la experiencia vivida (Lebenswelt) y, en un segundo movimiento de reducción, las estructuras del mundo de la experiencia se reinsertan en la corriente trascendental de una constitución universal, por medio de la cual las oscuridades del mundo quedan elucidadas. Aquí, nos encontramos ante un dilema: o bien dicha constitución hace transparente el mundo, en cuyo caso habría que explicar por qué es necesario hacer un rodeo a través de la experiencia; o bien retiene siempre algo de ese mundo y no lo libera del todo de su opacidad. La filosofía tardía de Husserl parece decidirse por este segundo camino.

Hemos afirmado con Merleau-Ponty el carácter trascendental de la intersubjetividad. ¿Podría este hecho poner en peligro la identidad del hombre singular? López Sáenz aclara que nuestra intercorporeidad constitutiva "no anula, sin embargo, la transcendencia de cada ser singular. Ésta procede justamente del descentramiento de la situación compartida que conduce a la intersubjetividad" (López Sáenz, 2007, p. 99). Si el ser carnal tiene multitud de rostros y pliegues, ello se debe a que es el elemento que se halla en medio de cada uno de nosotros, moldeado, ensanchado, y menguado en nuestras relaciones intercorpóreas. De este modo, ninguna existencia humana será baladí ni gratuita, cada individuo singular constituye uno de los ángulos que dan forma al mundo, y su existencia es, en cada momento histórico, necesaria para que el mundo sea, en un paulatino acto de expresión por el cual se hace visible lo invisible. Lo que garantiza la unidad de la experiencia del propio cuerpo y de su intencionalidad hacia el mundo es el esquema corporal, el cual no es una representación estática de las distintas partes del cuerpo, sino la integración dinámica de las mismas en los proyectos motores del organismo. Si la dualidad del en-sí-para-sí es ahora con Merleau-Ponty experiencia vivida de mi existencia encarnada en el cuerpo que se abre continuamente al mundo, el ser y la nada devienen en lo visible y lo invisible del ser. En efecto, en la ontología merleaupontiana la negación será privación de visibilidad en el mismo ser carnal (chair). López Sáenz introduce en su ensayo El cuerpo, perspectivas filosóficas las nociones, expresadas por Merleau-Ponty en Signes, de mundo salvaje y espíritu salvaje. "Este 'Ser Salvaje' es movimiento anclado en el suelo (Boden) en el que vivimos, que engloba todo lugar, y lleva a todos los vivientes más allá de la nada" (López Sáenz, 2002, p. 195). En Lo visible y lo invisible el ser salvaje es llamado "ser vertical", el ser trascendente que "introduce" la negatividad en la carne (chair). Entrecomillamos "introduce" para señalar la distancia respecto del gesto soberano del para-sí sartreano que insertaba la nada en el ser. El ser vertical se ancla siempre en el suelo de la experiencia. Podemos concluir la valoración de esta transformación en la fenomenología de la existencia afirmando la principal consecuencia que tiene para la ontología: si Sartre plantea su ontología desde la nada para ir desde el lugar del para sí al encuentro del ser, en Merleau-Ponty hallamos una ontología positiva del ser, en la cual no se asiste a la determinación 
del ser rodeándolo por un borde de nada, sino al proceso afirmativo de continuo desvelamiento de la Idea escondida tras el ser carnal, la continua expresión de lo no verbalizado, la conversión de lo invisible en visible. La negatividad en Merleau-Ponty es negación de visibilidad de la carne, no es la carencia de ser sino el exceso de ser de la carne, que se extiende más allá de lo visible.

\section{Un nuevo modo de comprender el problema de la libertad y la responsabilidad}

En el último capítulo de la Fenomenología de la percepción, Merleau-Ponty critica el concepto sartreano de libertad. Si bien para ambos pensadores, el sujeto se propone fines y valores como proyectos, dando así un futuro a su vida, si para ambos la libertad es siempre libertad anclada en mis posibilidades presentes y en mis elecciones pasadas, y consiste en el proyecto de un compromiso de participar en nuevas relaciones existenciales futuras, para Merleau-Ponty soy “ una estructura psicológica e histórica" y he adoptado a lo largo de mi existencia hábitos y formas de ser, a partir de los cuales actúo y pienso. Vimos de qué modo concebirá en Lo visible y lo invisible la ampliación de sentidos del lenguaje y la trascendencia más allá de los significados compartidos y adquiridos institucionalmente en el diálogo con otros, como la adopción de un nuevo gesto. Si soy libre para trascender las determinaciones que se me imponen desde fuera, esto no se debe a que, como cree Sartre, nada actúe sobre mí y pueda, haciendo ejercicio de mi libertad, sustraerme por completo a tales determinaciones, pues por el contrario me encuentro siempre abierto al mundo.

En su trabajo Figuras de la libertad en Merleau-Ponty, Eduardo Bello describe las acepciones que toma la libertad en la Fenomenología de la percepción: como libertad situada, la libertad merleau-pontiana radicaliza el anclaje de mi libertad en mi situación presente y pasada, pues pese a que Sartre reconozca el carácter situado del que parte mi libertad, concibe en última instancia que por medio de ella puedo sustraerme a dicha situación, confiere a mi proyecto una absoluta autonomía respecto de mis circunstancias actuales. "El problema es si toda situación dada tiene ya un sentido" (Bello, 2008, p. 168), si mi pertenencia a un contexto intersubjetivo posee por sí misma un sentido o si, más bien, el sentido es un valor que atribuyo de manera plenamente autónoma a la experiencia. La libertad absoluta sartreana es subsidiaria de su comprensión del para-sí: solo si me concibo a distancia respecto de mí mismo y respecto del mundo puedo radicalizar las posibilidades de mi ruptura con el pasado y el entorno. Para Merleau-Ponty las acciones realizadas en el mundo intercorpóreo e intersubjetivo no son meras constricciones que limiten mis posibilidades y de las cuales- en tanto que ajenas y en cierto sentido exteriores- pueda liberarme de una vez por todas. Una vez que entramos en el juego de la implicación en el mundo, nos comprometemos y dichas formas que adquiero en mi vida con otros no son una mera superficie, no es un rol ni un papel que juego sin llegar a creerme nunca del todo, como sugiere Sartre en El ser y la nada. Esas "determinaciones" son hábitos que penetran 
todo nuestro modo de ser, de tal manera que, si podemos romper con ellos, no será sino por medio de la adopción de nuevos hábitos en próximas prácticas. La noción de hábito merleau-pontiana será central para entender, además, en qué sentido el hombre es un individuo histórico: al igual que las prácticas intersubjetivas actuales, la historia no es una mera sucesión de episodios que precedan al momento presente, y determinen una situación que me es por completo ajena y de la cual puedo desprenderme. Al explorar la constitución de la Carne hemos expuesto cómo esta se compone de diversos rostros al quedar inscrita en las cosas la visibilidad y la tangibilidad que adquirieron en el trato con otros: si nos las vemos en el mundo con cosas vistas y tocadas por otros, podemos decir que la Historia no es una mera superposición de momentos que se nieguen y se superen entre sí: está metida en el mundo en que nos encontramos, inserta en la Carne, como la piel que cubre con un sentido a las cosas.

En segundo lugar, como apertura al mundo, mi libertad se da en contacto con un ser que no está plenamente constituido y que nos ofrece él mismo posibilidades de ser futuras. Si para Sartre, la posibilidad de ser le resultaba ajena al ser-en-sí por ser este plenitud de ser, de tal manera que sería el para-sí quien, por contar con la posibilidad como estructura de su modo de ser, introduciría la negatividad de la posibilidad en el ser, para Merleau-Ponty el ser de la carne (chair) tendrá en sí mismo cierta indeterminación. Por no ser él mismo constituido de una vez por todas - como tampoco lo es el mundo- el hombre tendrá que hacerse continuamente a sí mismo. En la conferencia La filosofía de la existencia, Merleau-Ponty señaló cómo con su idea absoluta de libertad, Sartre se distanciaba del marxismo, que hacía depender al sujeto de las circunstancias externas. La propuesta de Merleau-Ponty, si bien sitúa al individuo en campos de prácticas intersubjetivas que lo constituyen, niega el determinismo, no afirmando el poder del hombre para romper con toda suerte de determinaciones, sino atendiendo al modo en que dichas prácticas conservan siempre una cierta indeterminación, pues por ser performativas y simbólicas están siempre abiertas a nuevas posibilidades de orientación. Este es el tercer sentido de libertad que reconoce Bello en la Fenomenología de la percepción, la libertad proteica, como capacidad de ir más allá de lo que nos es dado; no negándolo y partiendo de un comienzo absoluto, sino asumiendo eso que nos es dado y transformándolo. Finalmente, Bello alude a la libertad política en Merleau-Ponty, la cual consistiría en la propuesta de un pluralismo político expresivo del pluralismo ideológico y social que buscará instaurar en el terreno intersubjetivo instituciones que garanticen y conserven dicha libertad.

Las consecuencias éticas del planteamiento de la libertad sartreano aparecían bosquejadas al final de El ser y la nada y reformuladas en El existencialismo es un humanismo. En este ensayo, Sartre disuade al lector de interpretar el planteamiento de la obra anterior como una proclama de inmoralidad, de retirada del hombre a un individualismo que renunciase a toda acción sobre el mundo. Sin embargo, pese a su intención moral, la filosofía sartreana presenta ciertos obstáculos a la moralidad, pues desconfía del mundo intersubjetivo y su consideración de las instituciones en la Critique, las reduce al rango de meros 
parches con los que impedir el desplome de los grupos en la serialidad de los individuos separados. Para Merleau-Ponty, en cambio, la institución no será ya un mero dispositivo para contener el aislamiento latente que finalmente se imponga, porque en la creación de esas instituciones se vence ese aislamiento, de manera que los individuos quedan comprometidos sin renunciar a su singularidad. La libertad, como proyecto al que el hombre está condenado, implica en Sartre la absoluta responsabilidad del individuo respecto de su acción y de cada una de sus elecciones Los objetivos y fines que el hombre persigue no son nada si el hombre no los vive, es decir, si no se determina libremente en su existencia por relación con ellos. Para Sartre, entonces, también construyo mi libertad eligiendo continuamente, si bien sustrayéndome a mis constricciones y no, como sucede en Merleau-Ponty, comprometiéndome y restringiendo mi libertad a la vez que la afirmo. Frente a la idea de libertad sartreana que deja todo el peso de la responsabilidad en el individuo, para Merleau-Ponty, dicha libertad está sujeta a la unión de lo dado y lo construido. Viviendo en un mundo intersubjetivo, la responsabilidad individual se dará siempre en conjunción con la responsabilidad colectiva y, además, el peso de mis acciones quedará incrementado en comparación con la situación sartreana: mi responsabilidad en las acciones que realizo ya no tiene solo consecuencias para las decisiones que tomo para-mí delimitando mis posibilidades, sino que por medio de esas acciones afecto a los otros y al mundo construido con ellos. De esta manera lejos de aminorarse el sentido de la responsabilidad en la filosofía de Merleau-Ponty, se enfatiza la importancia de la acción de cada individuo en relación con las totalidades intersubjetiva e históricamente construidas.

\section{Referencias}

Bello Reguera, E. (1979). De Sartre a Merleau-Ponty: dialéctica de la libertad y del sentido. Murcia: Universidad de Murcia.

Bello Reguera, E. (2008). Figuras de la libertad en Merleau-Ponty. Murcia: Universidad de Murcia.

Heidegger, M. (2006). Sein und Zeit. Tübingen: Max Niemeyer.

Kwant R. C. (1963). The phenomenological philosophy of Merleau-Ponty. Pittsburgh: Duquesne University Press.

López Sáenz, M. C. (1998). Merleau-Ponty o el arte de la visibilidad. Ágora: Papeles de filosofía, 17(2), 145-165.

López Sáenz, M. C. (2003). Imaginación carnal en Merleau-Ponty. Revista de filosofía, 28(1), 157-169.

López Sáenz, M. C. (2007). Identidad lateral. Un concepto de la fenomenología, Berceo, (153), 97-129. 
López Sáenz, M. C. (2010). Hermenéutica del cuerpo doliente-dolido desde la fenomenología del sentir. Investigaciones fenomenológicas: Anuario de la Sociedad Española de Fenomenología, (2), 89-123.

López Sáenz, M. C., Rivera De Rosales, J. (Coords.) (2002). El cuerpo. Perspectivas filosóficas. Madrid: Universidad Nacional de Educación a Distancia.

Merleau-Ponty, M. (1945). Phénoménologie de la perception. París: Gallimard.

Merleau-Ponty, M. (1964). Le visible et l'invisible. Paris: Gallimard.

Merleau-Ponty, M. (2009). La fenomenología de la existencia. Praxis Filosófica, (28), 229-242. [Traducción del artículo publicado en la revista Dialogue, (3), 307-322, de 1966].

Sartre, J. P. (1963). Crítica de la razón dialéctica. Buenos Aires: Losada.

Sartre, J. P. (1966). La transcendence de l'ego. Esquisse d'une description phénoménologique. París: Vrin.

Sartre, J. P. (1976). El ser y la nada: ensayo de una ontología fenomenológica. Buenos Aires: Losada.

Sartre, J. P. (1989). Verdad y existencia. Barcelona: Paidós.

Sartre, J. P. (1992). El existencialismo es un humanismo. Barcelona: Edhasa.

Sartre, J. P. (2008). La náusea. Buenos Aires: Losada.

Sellés, J. F. (Coord.) (2004). Modelos antropológicos del siglo xx: M. Scheler, D. von Hildebrand, E. Stein, M. Merleau-Ponty, J. P. Sartre, H. Arendt. Pamplona: Universidad de Navarra.

Zaner R. M. (2013). The problem of embodiment: Some contributions to the phenomenology of the body. La Haya: Martinus Nijhoff. 